\title{
Policy Durability, Agency Capacity, and Executive Unilateralism1
}

\author{
Ian R. Turner \\ Department of Political Science \\ Yale University \\ ian.turner@yale.edu
}

\begin{abstract}
In this essay I argue that the need to motivate bureaucrats to invest in high quality policy implementation alters the appeal of executive unilateralism. If executive orders are less durable than legislation, then the bureaucracy will have weaker incentives to invest in policymaking. This affects presidents' willingness to compromise and work with Congress to pass legislation, rather than pursue unilateral action. Unilateralism becomes less attractive as bureaucratic capacity increases and as the relative durability of executive orders decreases. I formalize this logic in a simple formal model and discuss fruitful extensions for future work.
\end{abstract}

1 I would like to thank John Patty, Will Howell, John Dearborn, Sharece Thrower, Dave Lewis, Andrea Aldrich, and Jon Rogowski for helpful discussions about this essay. Of course, all errors are my own. 


\section{Introduction}

As more power has become concentrated in the presidency interest in executive unilateral action has increased.2 Executive orders carry the full force of law, provided they do not explicitly violate the Constitution or statutory authority, and do not require formal acquiescence from the other branches (Cooper 2002; Mayer 2001). This raises concerns that increasing usage of executive unilateralism may undermine normative principles underlying separation of powers. Accordingly, scholars have focused on studying the determinants of unilateral action with a focus on what might constrain its usage.

The principal constraints on unilateral action are the legislature and the judiciary since both institutions have the ability to effectively veto executive orders (e.g., Bolton and Thrower 2016; Chiou and Rothenberg 2014, 2017; Howell 2003; Moe and Howell 1999). In addition, recent research suggests that the public's disdain for executive unilateralism may constrain its usage even if formal instutitional constraints do not (e.g., Christenson and Kriner 2019; Lowande and Gray 2017; Reeves and Rogowski 2015, 2016, 2018).3 Regardless of the types of constraints being studied, the primary focus is often on the struggle between the president and Congress for policy supremacy. Indeed, concern toward over-accumulation of executive power is based, in part, on the idea that shifting too much power away from Congress to the presidency is undesirable because it throws off the balance of power across branches. In this essay, I provide insight into a straightforward question: When does a president eschew working with Congress to pass legislation to instead act unilaterally by, for example, issuing an executive order? Put

2 See Mayer 2009 for a review.

3 See Judd 2017 for related arguments highlighting how electoral incentives may drive unilateralism in ways that reduce voter welfare. 
another way, what dynamics affect the relative attractiveness of executive unilateralism compared to the pursuit of interbranch legislation?

In what follows I develop a straightforward argument that sheds light on these questions. Specifically, I study a model of policymaking that incorporates several stylized facts from extant literature into one, flexible framework. I first assume that executive orders are less durable than legislation. That is, unilateral action is relatively easier to overturn or reverse, perhaps by future administrations, than a statute passed by Congress (Thrower 2017). Second, I incorporate insights from research on bureaucratic politics highlighting the importance of incentives for bureaucrats to invest in information, expertise, or, more broadly, high quality policymaking (e.g., Gailmard and Patty 2013b).4 This is an important consideration for studying how the appeal of unilateral action, relative to working with Congress, changes based on the quality of the administration below the chief executive. Regardless of policy instrument - unilateral action or legislation - implementation typically relies on another institution: the bureaucracy.

The basic logic I formalize in this essay is as follows. The overall quality of implemented policy depends on the bureaucracy's willingness to invest in that quality, which is also impacted by its capacity. This agency capacity could be analytic (informational) or programmatic (implementation) or both (Carpenter 2001). It does not matter for the argument how one interprets the exact substantive nature of this capacity so long as it lowers the marginal cost of agency-provided policy quality. Regardless of policy instrument higher capacity agencies invest more toward policy quality than lower capacity agencies. However, the type of policy instrument chosen does affect a given agency's willingness to invest due to differential policy durability. If

4 See also Gailmard and Patty 2007; Ting 2011; Turner 2017 for work in this vein. 
an agency is asked to implement policy promulgated by legislation the agency can expect that policy to live on into the future due to the difficulties of repealing laws in Congress.5 On the other hand, the bureaucracy's incentives to invest following an executive order are weaker precisely because of the lack of policy durability. When the expected life-cycle of a policy is shorter investments in administering that policy are riskier from the perspective of bureaucrats. Why make large administrative investments if you expect them to be wasted due to future policy reversal? Thus, the bureaucracy will invest more in policy quality when the policy it is asked to administer is more durable, which implies the bureaucracy will 'work harder' when asked to implement a statute relative to an executive order. This, in turn, makes unilateral action less attractive compared to working with Congress to pass a more durable policy through the legislative process.

Of course, if working with Congress to pass a piece of legislation requires ideological compromise then the president may dislike that option even though it leads to higher effort from the bureaucracy. If the president can bypass Congress by issuing an executive order she can also

5 One of the oft-mentioned differences between presidential unilateralism and Congressional processes is that Congress faces severe collective action problems relative to the president and, somewhat relatedly, the president also may have an informational advantage over Congress. These problems may make legislation much harder to roll back than executive orders. See, for example, (Howell and Pevehouse 2007; Lewis and Moe 2014; Mayer 2001; Moe and Howell 1999) for research highlighting these collective action problems and (Canes-Wrone 2006) on the president's informational advantage. See (O'Brien 2017) for recent criticism of these arguments. 
pursue policy based mostly on her own interests. 67 Therein lies the fundamental trade-off for the president that I highlight in this essay: executive unilateralism allows presidents to pursue policies closer to their ideal policy than might be possible if policy is instead made through interbranch bargaining, but this also leads to weaker incentives for the bureaucracy to invest in producing high quality policy outcomes. Explicitly incorporating the need to motivate agency's to invest in quality implementation changes the dynamics of interbranch bargaining.

Specifically, policy durability and bureaucratic capacity jointly determine how attractive interbranch bargaining is compared to unilateral action. As executive orders become more durable the president becomes less willing to compromise ideologically in order to work with Congress to pass legislation. Conversely, as executive orders become more tenuous the chief executive is more willing to compromise to lock in long-lived legislation even at the cost of policy substance. Of course, as executive order durability decreases the bureaucracy becomes less and less willing to invest much in the way of policy quality. Thus, the quality gap between legislation and executive orders grows (decreases) as durability of unilateral action decreases

${ }_{6}$ Of course, even given reasonably wide latitude it is likely the president takes other institutions such as courts and the legislature into account when designing executive orders, as is highlighted in (Chiou and Rothenberg 2017) and (Howell 2003) for example. Similarly, executive orders often involve intrabranch bargaining within the executive branch (Rudalevige 2012). The argument I develop here is not fully dependent on the president having unfettered control of policy location. So long as executive orders more closely reflect the president's preferences relative to competitive actors then the basic logic holds up. As long as bargaining with, for example, Congress requires some compromise then the trade-off I highlight is potentially present.

7 This point follows in part from the assumption that the president has a form of first-mover advantage. As will be clear below, I formalize this by allowing the president to move first and issue an executive order or propose a policy to Congress. For other work employing the general assumption that the president has first-mover advantages see, e.g., (Howell 2003; Howell and Pevehouse 2007; Lewis 2003; Moe and Howell 1999; Wood 2008; Zeisberg 2013) and for criticism of this assumption in some domains see (O’Brien 2017). 
(increases). Higher capacity agencies always invest more in policy quality - indeed, this is what makes them high capacity. As agency capacity increases so does the relative appeal of passing legislation over issuing executive orders. This is because the quality gap between legislation and executive orders is increasing in agency capacity, holding policy durability fixed. Interestingly, this implies that, all else equal, as the administration the chief executive oversees becomes more high quality involving the legislative branch to lock in stable policy change becomes more attractive even when this requires ideological compromise.

Previous research recognizes both of the factors that drive these insights. (Thrower 2017) provides recent research exploring the determinants of executive order revocation. She argues that, "future regimes can easily change policies, particularly presidents who can act independently from other political actors through unilateral action" (p. 643).8 Even though executive orders carry the force of law they are structurally easier to revoke by future administrations in particular. Similarly, many scholars have recognized the general fact that policy directives do not simply execute themselves but instead rely on administration to do so (e.g., Dickinson 2009; Howell 2005; Kennedy 2015; Krause 2009; Krause and Dupay 2009; Lowande 2018; O’Brien 2017; Rudalevige 2012).9 Put simply, the idea that there are no implementation problems once a directive is issued seems to miss important political considerations when executives consider whether or not to bypass the legislative process in favor of unilateralism (Rudalevige 2009). Similar to the goals in this essay, Lowande 2018 also begins from the premise that the bureaucracy is relied upon for implementation regardless of whether

8 See also Foster 2019 for a recent argument that interest group participation and policy feedback impact the durability of unilateral action. 9 See also Burke 2000, Miller 1993, and Nathan 1983 for work highlighting how issues of managerial control within the executive branch affect efforts to change policy. 
Congress passes a law or the president issues an executive order. Lowande characterizes when the president would delegate to an insulated versus uninsulated agency while using an executive order, which, in part, depends on the nature of interbranch relations. I complement the arguments in Lowande 2018 by focusing on how including the bureaucracy affects interbranch bargaining dynamics, which ultimately affects how attractive executive unilateralism is as a tool for policy change itself. Ultimately, I hope that the argument I develop in this essay serves as a jumping-off point for future analysis that incorporates more of the rich political-institutional details scholars have highlighted in previous work on the topic.

\section{A model of unilateral action with bureaucracy}

To illustrate the dynamics discussed above, I analyze a simple model of interbranch bargaining with endogenous policy quality. The model is purposely sparse in order to formalize the logic described informally in the introduction in the most stark and simple way possible. Later I discuss a few ways future research might layer on more rich institutional environments and political considerations.

There are three players engaged in a policymaking game: a President $(P)$, Congress $(C)$, and a bureaucratic Agency $(A)$. The policy space is unidimensional and is represented by the real line $\mathbb{R}$. Each actor has an ideal point: $P \in \mathbb{R}, C \in \mathbb{R}$, and $A \in \mathbb{R}$. To aid in exposition I assume that $C<P$ so that the President's ideal point is to the right of Congress.10 There is an exogenous status quo policy denoted by $x_{Q} \in \mathbb{R}$.

10 As will become clear below, the location of the Agency's ideal point is inconsequential for the results because I suppress the Agency's ability to move spatial policies. In a more general model, of course, the location of Arelative to $P$ and $C$ would also matter. 
Following previous work (e.g., Howell 2003; Mayer 2001), the President has a firstmover advantage. She chooses whether to issue an executive order $(E O)$ or to propose a statute $(S)$ to Congress. These choices are represented by $x_{E O} \in \mathbb{R}$ and $x_{S} \in \mathbb{R}$, respectively. If the President chooses to propose a statute then Congress observes the proposal, $x_{S}$, and chooses whether to accept the proposal or not. If Congress rejects the President's proposal then final policy, denoted by $x^{*}$, is the status quo $x^{*}=x_{Q}$. The Agency, if an executive order is issued or a statute is successfully passed, makes a costly investment in 'quality,' which is denoted by $q \geq 0$. This quality investment does not alter the policy's spatial location, but it does increase the attractiveness of the policy, holding its ideological location fixed. I interpret this as improving the overall implementation of policy, which is commonly valued by all the players. Everyone likes higher quality policies, all else equal.11 However, the Agency must pay a quality cost denoted by $c(q):=\frac{q^{2}}{2 \lambda}$ where $\lambda>0$ measures the Agency's capacity. Larger (smaller) $\lambda$ captures higher (lower) capacity, which translates into a lower (higher) marginal cost of quality.

In order to capture the differential durability of policy instruments I assume that successfully adopted statutes are always implemented with certainty while executive orders only end up being implemented with probability $p \in(0,1)$. That is, if the President issues an executive order then the Agency invests $q_{E O}^{*}$ in quality but the executive order becomes final policy with probability $p$ (i.e., $x^{*}=x_{E O}$ with probability $p$ ) and the status quo becomes final policy with probability $1-p$ (i.e., $x^{*}=x_{Q}$ with probability $1-p$ ). In this way, executive orders

11 This is akin to models of policymaking with valence (e.g., Hirsch and Shotts 2012, 2015), which have been employed to study, for example, interbranch bargaining (Londregan 2000), legislative policymaking (Hitt, Volden, and Wiseman 2017), lobbying and special interest politics (Hirsch and Shotts 2018; Hübert and Rezaee 2019), and bureaucratic expertise (Ting 2011; Turner 2017, 2019a, 2019b), among other things. 
are less durable than statutes. The Agency is a non-strategic player in the sense that I assume that it cannot move the spatial location of policy. It only invests in quality as a function of costs $c(q)$, which are further dependent on the Agency's capacity $\lambda$. Of course, one can easily adapt the model to incorporate other important considerations such as bureaucratic discretion (Epstein and O’Halloran 1994, 1999), interbranch oversight (Epstein and O'Halloran 1995; Patty and Turner 2019), or differential policy complexity (Callander 2011; McCarty 2017). I discuss several such possibilities in the discussion section below.

Each player values policy quality $q$ and also strictly prefers final policies as close to their respective ideal points as possible. To capture these motivations each players' utility function is given by the following expressions:

$$
\begin{array}{llc}
u_{P}\left(q, x^{*}\right)= & q-\left(x^{*}-P\right)^{2} \\
u_{C}\left(q, x^{*}\right)= & q-\left(x^{*}-C\right)^{2} \\
u_{A}\left(q, x^{*}\right)= & q-\left(x^{*}-A\right)^{2}-\frac{q^{2}}{2 \lambda} .
\end{array}
$$

As these functions show, all players prefer higher quality policies that are as close as possible to their respective ideal points, but only the Agency directly bears the costs of improving policy quality $\left(c(q):=\frac{q^{2}}{2 \lambda}\right)$.

Because this is a sequential game of complete information I focus on subgame perfect Nash equilibrium; hereafter referred to simply as 'equilibrium.' An equilibrium consists of a profile of strategies that includes a policy choice strategy for the President, an acceptance strategy for Congress, and a quality investment strategy for the Agency in which each player is playing equilibrium strategies at each subgame. In other words, every player maximizes their utility given the equilibrium strategies of the other players. 


\section{Comments on modeling assumptions.}

It is worth taking a moment to discuss some of the assumptions in the model described above. First, I treat legislation as perfectly durable and executive orders as less durable. In reality, it is, of course, possible to overturn a statute by passing another statute and some executive orders end up being incredibly durable.12 Nonetheless, I make this assumption to capture the idea that in many cases legislation is less easy to change than an executive order in expectation. I then use this observation, coupled with differential agency capacity, to draw out implications for the relative allure of unilateral action as expectations of durability vary.

Substantively, $\boldsymbol{p}$ captures challenges to executive order durability such as limited presidential discretion or differential partisan influence (Chiou and Rothenberg 2017; Howell 2003), constraints introduced through public opinion (Judd 2017; Reeves and Rogowski 2018) or interest groups (Foster 2019), or other political determinants of executive order tenure (Thrower 2017). All of these represent model extensions that could be layered onto the baseline framework developed in this essay. I discuss some of these possibilities in the discussion section below.

I also assume that if the President proposes a statute and Congress elects not to pass it that the game ends with final policy being the status quo. Substantively, this captures the idea that when the President pushes a legislative agenda and it fails to pass in Congress political capital has been expended and it is no longer politically viable to move forward with unilateral action. Of course, an alternative would be to allow the President to respond with an executive order, perhaps with a political cost for having failed to have a legislative priority passed. This

12 It is also worth noting that legislation being perfectly durable in the model is inconsequential for the qualitative results, this is only a normalization. What matters is relative durability across policy instruments, which is captured simply by $p$. 
would yield the President more leverage in the bargaining environment. While this may be an interesting extension it is one I leave to future work. Similarly, one could allow Congress to respond to the President's initiative by not only vetoing, which leads to retention of the status quo, but by setting its own policy. This is the approach in, for example, Howell 2003. It would also be straightforward to incorporate that into the model here. Given the goals of this essay I assume the veto to keep the focus on the impact of durability and agency capacity specifically, but one way to think about this assumption is that $C$ represents the ideal point of the pivotal legislator and, therefore, if the President pursues legislation with Congress then the pivotal legislator's preferences will be incorporated upstream in the President's proposal itself. This is, in fact, the same dynamic as in work such as Howell 2003. While the model in this essay abstracts away from some of those nuances, which are important and fodder for future work, the departure is not overly substantively restrictive given the focus here.

Finally, I assume that the Agency cannot affect the spatial location of policy. That is, the Agency is non-strategic in that it only chooses a level of investment in policy quality, which is mechanical. This is obviously a very strong substantive assumption that future work should relax. However, in this context it is a useful assumption in that it isolates the key trade-off of interest in this essay. By only focusing on endogenous quality investment the model will illustrate how even this simple inclusion alters the dynamics of interbranch bargaining between the President and Congress. Specifically, the need to provide investment incentives, coupled with the differential durability across policy instruments, alters how attractive unilateral is vis-á-vis legislative cooperation depending on characteristics of the agency and the policy environment. In this discussion section I explore some avenues for relaxing this assumption. 


\section{Equilibrium agency quality investments}

To begin the analysis, I first characterize the Agency's equilibrium quality investments. As noted above, the Agency cannot shift substantive policy and so serves a non-strategic player who simply chooses $q$, conditional on the type of policy it is tasked with implementing, to maximize its utility. There are two key characteristics of the environment that drive bureaucratic quality investments: agency capacity and relative policy durability. The former is captured by $\lambda$ and the latter by $p$. Formally, when the President and Congress pass a statute that the Agency is tasked with implementing the Agency invests $q_{S}$ that solves the following problem,

$$
\max _{q}\left[q_{S}-\left(x_{S}^{*}-A\right)^{2}-\frac{q^{2}}{2 \lambda}\right],
$$

which yields the Agency's equilibrium quality investment given that the policy it implements is a statute:

$$
q_{S}^{*}=\lambda
$$

Because statutes are normalized to be 'fully durable', in the sense that the policy will definitely go into effect, the Agency need not worry about its quality investments being made in vain. Whatever they invest in policy quality will be realized. Thus, the overall level of investment by the Agency, given a statute was passed, depends only on the Agency's capacity in that policy area, $\lambda$. The higher capacity the Agency has the lower the marginal cost of quality is, which translates into overall higher quality investment.

Suppose now that instead of pursuing statutory policy, the President bypasses Congress and issues an executive order. In that case the Agency invests $q_{E O}$ that solves its analogous problem when implementing an executive order, 


$$
\left.\max _{q}\left[p\left(q_{E O}-\left(x_{E O}^{*}-A\right)^{2}\right)-(1-p)\left(x_{Q}-A\right)^{2}\right)-\frac{q^{2}}{2 \lambda}\right]
$$

which yields the Agency's equilibrium investment when the policy is an executive order:

$$
q_{E O}^{*}=p \lambda .
$$

In this case the bureaucracy must incorporate the risk that the executive order will be short-lived into its investment decision. Since executive orders, relative to statutes, are less durable the Agency has weaker incentives to invest in policy quality. As before, higher capacity is good news for policy quality but now, in contrast to Agency decision-making following statutory policymaking, the less durable executive orders are the less quality the Agency will invest in (i.e., $q_{E O}^{*}$ decreases as $p$ decreases). As discussed above, $p$ can reflect important considerations like the discretion the President has in a particular policy area or the likelihood of the executive order surviving judicial oversight (Howell 2003), or any other political determinant of executive order precariousness (Thrower 2017). The key insight is that when bureaucratic incentives to work to implement policy well are endogenous, the (lack of) durability of executive orders harm those incentives relative to statutory routes to policy change and overall quality investments are lower.

Proposition 1. For all $p \in(0,1)$, the agency's quality investment is lower following an executive order than a statute: $q_{S}^{*}=\lambda>q_{E O}^{*}=p \lambda$. Moreover, $q_{E O}^{*} \rightarrow 0$ as $p \rightarrow 0$ and $q_{E O}^{*} \rightarrow q_{S}^{*}$ as $p \rightarrow 1$.

There are a few aspects of Proposition 1 worth noting further. First, as executive orders become more durable - the President has more discretion, there are no legal questions about the policy, it is politically popular - the 'quality gap' between statutes and executive orders decreases. Second, all else equal, as agency capacity increases so does the quality gap between statutes and executive orders. That is, for a given level of executive order durability as $\lambda$ increases the difference between $q_{S}^{*}$ and $q_{E O}^{*}$ also increases. 
Overall, the analysis in this section illustrates how agency capacity and policy durability interact to affect bureaucratic policymaking incentives. Executive order durability and agency capacity jointly determine the gap in quality investments across policy instruments. This structures the trade-offs associated with statutes versus unilateral action, the analysis of which I turn to next.

\section{Equilibrium policymaking: Statute or executive order?}

In this section, I characterize equilibrium policymaking given agency quality investment strategy characterized above. First, I characterize Congress's acceptance set, or the set of proposed statutes that Congress would accept over the status quo. Second, given Congress's acceptance set, I analyze the President's choice of policy instrument by characterizing her proposal set: the set of policies that the President would propose to Congress instead of pursuing an executive order.

\section{Congressional acceptance set.}

Congress has the ability to reject statutory proposals in favor of retaining the status quo. Of course, it will only pass policies that are better, both in terms of spatial location and the quality invested by the implementing agency, than the status quo. That requires that $\boldsymbol{u}_{\boldsymbol{C}}\left(\right.$ accept $\left.\mid \boldsymbol{x}_{S}, \boldsymbol{q}_{S}^{*}\right)=\boldsymbol{q}_{S}^{*}-\left(\boldsymbol{x}_{S}^{*}-\boldsymbol{C}\right)^{2} \geq \boldsymbol{u}_{\boldsymbol{C}}\left(\right.$ reject $\left.\mid \boldsymbol{x}_{\boldsymbol{Q}}\right)=-\left(\boldsymbol{x}_{\boldsymbol{Q}}-\boldsymbol{C}\right)^{2}$, which is satisfied for all proposed statutes $\boldsymbol{x}_{\boldsymbol{S}}$ that fall in the following range:

$$
x_{S} \in\left[C-\sqrt{q_{S}^{*}+\left(x_{Q}-C\right)^{2}}, C+\sqrt{q_{S}^{*}+\left(x_{Q}-C\right)^{2}}\right]
$$

Define $\Delta_{C}:=\sqrt{q_{S}^{*}+\left(x_{Q}-C\right)^{2}}$ as the spatial deviation from Congress's ideal point $C$ for which 
it will still pass a proposed statute rather than reject and retain the status quo. Congress will pass any statute that is closer to its ideal point than $\Delta_{C}$ and reject any statute that is further from $C$ than $\Delta_{C}$.

Lemma 1. In equilibrium, Congress accepts a proposed statute $x_{S}$ if and only if $x_{S} \in[C-$ $\left.\Delta_{C}, C+\Delta_{C}\right]$. Otherwise, Congress rejects the proposed statute and the status quo obtains. The range $\left[C-\Delta_{C}, C+\Delta_{C}\right]$ is increasing in Agency quality investments $q_{S}^{*}=\lambda$ and the distance between the status quo and Congress's ideal point $\left|x_{Q}-C\right|$.

Lemma 1 also shows that $\Delta_{C}$ is increasing in both $q_{S}^{*}=\lambda$ and $\left|x_{Q}-C\right|$, which implies that the range of acceptable proposed statutes is increasing in agency capacity and as the status quo becomes less desirable. Consistent with standard spatial models, Congress is willing to pass statutes further from its ideal point the further the status quo reversion policy is from its ideal point. In addition, Congress is willing to accept proposed statutes further from its ideal point as the Agency's capacity $\lambda$ increases because policy quality $q_{S}^{*}$ increases as capacity increases. Having characterized what set of policy proposals Congress would be willing to pass we can now turn to the President's choice of policy instrument.

\section{Presidential proposal set.}

When will the President bypass Congress to pursue unilateral action? In order to answer this question, we must first understand the trade-offs the President faces. If the President issues an executive order then she targets her ideal point so that $\boldsymbol{x}_{\boldsymbol{E} \boldsymbol{O}}^{*}=\boldsymbol{P} .13$ This implies that the President will also never propose a statute that would be rejected by Congress. 14 The availability

13 The formal result can be found in the appendix, Lemma 3.

14 The formal result can be found in the appendix, Lemma 4. 
of an executive order means that the President can always target her ideal point even without Congress. However, from Proposition 1, the Agency invests less in quality when the President issues an executive order than when the President and Congress pass a statute. So, while the President can avoid sacrificing spatial policy losses when she issues an executive order she must also leave quality on the table if she does so. This is where the fundamental trade-off discussed in the introduction manifests. Executive orders allow the President to avoid policy concessions that may be required to pass a statute, but that comes at the cost of providing incentives for the bureaucracy to invest in policy quality due to the relatively lower durability of the policy instrument.

The logic above implies that the relevant condition for the President to pursue passing a statute with Congress over sidestepping Congress and issuing an executive order is $u_{P}\left(x_{S} \mid q_{S}^{*}\right) \geq$ $u_{P}\left(x_{E O}=P \mid q_{E O}^{*}, p\right)$

$$
\left.q_{S}^{*}-\left(x_{S}-P\right)^{2} \geq p\left(q_{E O}^{*}-\left(x_{E O}-P\right)^{2}\right)-(1-p)\left(x_{Q}-P\right)^{2}\right)
$$

which, noting that $x_{E O}^{*}=P$ and $x_{S}$ is accepted by Congress, is satisfied for all statutes that fall into the range:

$$
x_{S} \in\left[P-\sqrt{q_{S}^{*}-p q_{E O}^{*}+(1-p)\left(x_{Q}-P\right)^{2}}, P+\sqrt{q_{S}^{*}-p q_{E O}^{*}+(1-p)\left(x_{Q}-P\right)^{2}}\right] .
$$

Define $\Delta_{P}:=\sqrt{q_{S}^{*}-p q_{E O}^{*}+(1-p)\left(x_{Q}-P\right)^{2}}$ as the spatial deviation from the President's ideal point $P$ such that she would prefer passing a statute with Congress, even though it deviates from her ideal point, to issuing an executive order at her ideal point. As long as there is a potential statute $x_{S}$ that Congress will accept that is closer to $P$ than $\Delta_{P}$ the President will engage 
in interbranch policymaking rather than unilateral action. 15

Lemma 2. In equilibrium, the President will propose a statute $x_{S}^{*}$, rather than issue an executive order, if and only if $x_{S}^{*} \in\left[P-\Delta_{P}, P+\Delta_{P}\right]$. The range $\left[P-\Delta_{P}, P+\Delta_{P}\right]$ is increasing in Agency quality investment $q_{S}^{*}=\lambda$ and the distance of the status quo from the President's ideal point $\left|x_{Q}-P\right|$, and decreasing in executive order durability $p$.

Similar to $\Delta_{C}, \Delta_{P}$ is increasing in both agency capacity $\lambda$ and the distance between the status quo $x_{Q}$ and the President's ideal point, which implies that the set of statutes that the President would prefer to unilateral action is increasing in those parameters as well. However, in contrast to Congress, the President must also take into account the relative durability of executive orders. Specifically, $\Delta_{P}$ is decreasing in $p$, which implies that the President's proposal set is decreasing as the durability of unilateral action increases. There are two channels through which $p$ leads to proposal set contraction. First, as $p \rightarrow 1$ the location of the status quo relative to Pmatters less. This is because the President can always choose to issue an executive order exactly at her ideal point and when durability of that action is of no concern there is no risk of having it fail, which ultimately eliminates consideration of the status quo as a potential outcome. Second, as durability increases the quality gap between statutes and executive orders decreases, holding agency capacity $\lambda$ fixed. In the limit, as $p \rightarrow 1, q_{S}=\lambda$ and $q_{E O}=p \lambda$ are equivalent so there is no trade-off between statutes and unilateral action in terms of bureaucratic-produced policy quality. Overall, as executive orders approach perfect durability $(p \rightarrow 1)$, the deviation from $P$ the President is willing to accept to pass a statute is approaching a set that only contains her ideal point (i.e., $\Delta_{P} \rightarrow 0$ ) and the President would only ever propose a statute if she can 15 See Lemma 2 in the appendix for the formal result. 
propose her ideal point $x_{S}=P$ and have it passed by Congress.16

Combined with the analysis above, characterizing when the President will choose to propose a statute versus issue an executive order completes the equilibrium analysis. The following result states the collection of strategies that constitute an equilibrium.

Proposition 2. In equilibrium, the players play the following collection of strategies:

- The President proposes a statute $x_{S}^{*}$ if and only if $x_{S}^{*} \in\left[P-\Delta_{P}, P+\Delta_{P}\right]$ and it will be accepted by Congress. Otherwise, she issues an executive order targeting her ideal point, $x_{E O}^{*}=P$.

- Congress accepts a proposed statute $x_{S}$ if and only if $x_{S} \in\left[C-\Delta_{C}, C+\Delta_{C}\right]$. Otherwise, Congress rejects $x_{S}$ and the status quo $x_{Q}$ becomes final policy.

- $\quad$ The Agency invests $q_{S}^{*}=\lambda$ toward quality implementation when the policy it is implementing is a statute and invests $q_{E O}^{*}=p \lambda$ if the policy is an executive order.

Proposition 2 characterizes the equilibrium behavior for each player generally. However, it is also worth discussing how the President chooses $x_{S}$ when she prefers statutory policymaking over unilateral action. This depends crucially on the overlap of Congress's acceptance set and the President's proposal set. Of course, if there is no overlap then that means there is no statute that will jointly satisfy both Congress and the President and therefore the President will issue an executive order at her ideal point $x_{E O}^{*}=P$ and the Agency invests $q_{E O}^{*}=p \lambda$ in policy quality. Given the assumption that $C<P$ this is a case in which the upper bound of Congress's acceptance set, $C+\Delta_{C}$, is to the left of the lower bound of the President's proposal set, $P-\Delta_{P}$,

16 Technically, when $p=1$ the President is indifferent between policy instruments, assuming Congress would pass $x_{S}=P$, since both yield the same spatial location and quality level. 
so that there is no overlap between the sets of acceptable statutes.

When there is overlap between the two sets so that $P-\Delta_{P}<C+\Delta_{C}$ the President will propose a statute $x_{S}^{*}$ that Congress will subsequently pass. However, the location of $x_{S}^{*}$ depends further on the location of the President's ideal point relative to the upper bound of Congress's acceptance set. If $x_{S}=P<C+\Delta_{C}$ then the President can propose policy at her ideal point, Congress will pass it, and the Agency will ultimately invest $q_{S}^{*}=\lambda$ in policy quality. This is the best case scenario for the President as the trade-off between spatial policy and endogenous quality investments disappears: she can get her most preferred policy with maximal quality investment from the Agency. If instead $x_{S}=P>C+\Delta_{C}$ then the President will propose a statute as close to her ideal point as possible, which is the upper bound of Congress's acceptance set, $x_{S}^{*}=C+\Delta_{C}$. In this case the President does sacrifice some on spatial policy, compared to issuing an executive order at her ideal point, but still prefers the statutory route due to the issues of policy durability and the quality gap between statues and executive orders described above.

\section{Policy durability, agency capacity, and unilateral action.}

How does the appeal of unilateral action, relative to working with Congress to pass a statute, vary in policy durability and agency capacity? In this section, I discuss the dynamics of interbranch bargaining in light of these parameters. The following result states the result with respect to agency capacity.

Remark 1. All else equal, as agency capacity $\lambda$ increases both Congress and the President become more willing to compromise on spatial policy to pass a statute.

As agency capacity $\lambda$ increases both Congress's acceptance set and the President's 
proposal set expand increasing the possibility that they will overlap and statutory policymaking will occur in equilibrium. Substantively, and somewhat counter-intuitively, this implies that for a given level of executive order durability $p$, compromising and passing a statute becomes increasingly more attractive as bureaucratic capacity increases. The better the bureaucracy is at providing quality policy implementation the more valuable the stability of statutes becomes relative to unilateral action. Even at high levels of executive order durability the higher capacity the agency, the more attractive statutory policymaking is due to legislation being more durable.17 The next result speaks directly to the effect of relative policy durability on the allure of unilateral action.

Remark 2. All else equal, as executive order durability increases, $p \rightarrow 1$, the President is less willing to compromise on policy location in order to pass a statute and as executive order durability decreases, $p \rightarrow 0$, the President is more willing to compromise on policy location in order to have a statute implemented.

Policy durability only affects the President's willingness to compromise. As pincreases the President is less willing to compromise to pass a statute (i.e., the President's proposal set shrinks), which makes it less likely that the two sets will overlap and increases the appeal of bypassing Congress and pursuing unilateral action. Recent work suggests that presidents increasingly pursue major unilateral action when their approval ratings rise (Christenson and Kriner 2019). If we link increasing $p$ to public approval so that durability is (in part) a function

17 In a sense, this result suggests that the bureaucracy plays a role in securing more favorable policymaking processes from the perspective of Congress by making unilateral action, in some circumstances, less attractive. This is reminiscent of results in Lowande 2018, which finds that bureaucratic agency can aid in Congressional medians securing more desirable outcomes. While the reasoning in Lowande and this essay is different, there are subtle similarities worth noting. 
of the president's standing in the public then this result is consistent with this recent empirical work.18 Similarly, we could understand $p$ to capture the point in the President's term. That would imply that $p$ is highest in the beginning of the term, which is consistent with some previous work (Cooper 2001; Howell 2003).19 That is, the executive order, all else equal, is at its most durable at the beginning of the president's term, which implies that it is relatively more attractive according the dynamics in Remark 2.

Ultimately, the forces of policy durability and agency capacity work against one another. As the stability of unilateral action increases the President's willingness to compromise and work with Congress decreases. But when the agency that will implement policy has high capacity both Congress and the President value statutory policymaking more, which increases the appeal of interbranch compromise. Of course, the simple model analyzed above, while useful for clearly and concisely illuminating this trade-off, abstracts away from many interesting nuances. I discuss a few potential substantive extensions that can further illuminate when unilateral action is more or less attractive as a function of the political environment generally, and the bureaucracy in particular.

\section{Discussion: Extending the model}

The analysis above highlights how policy durability and bureaucratic capacity interact to structure executive incentives to pursue unilateral action. The model, however, can be thought of

18 Though see Lowande and Gray 2017; Reeves and Rogowski 2015, 2016, 2018 for evidence of public backlash to unilateral action and Christenson and Kriner 2017a, 2017b for arguments that also involve pushback from Congress or the courts. Insofar as these dynamics push $p$ down they would have the opposite effect on unilateral action desirability.

19 Though see Howell and Mayer 2005, which found that presidents also pursue unilateral action later in their terms. 
as a baseline model in the sense that it is straightforward to extend in several ways to provide more nuanced, and realistic, intuition about how the forces identified above interact in different political environments. In this way the basic logic can be embedded in many different environments of interest. I briefly discuss a few of these possibilities below, beginning with incorporating a strategic agency.

\section{Agency policymaking discretion.}

In the model above the Agency is essentially a non-strategic player that invests in policy quality based simply on the costs of doing so. We saw that higher capacity agencies invest more toward policy quality, and all agencies invest more when asked to implement statutes rather than executive actions. However, agencies are also strategic in how they design the actual substance of policy (Potter 2019). Indeed, even after politicizing an agency responsiveness to presidential prerogatives is far from guaranteed (Dickinson and Rudalevige 2004). In modeling terms, this involves allowing the Agency to shift spatial policy once authority has been delegated. In other words, the baseline model in this essay assumes the agency has no discretion when it comes to policy substance but of course discretion is a strategic choice in itself (Epstein and O'Halloran 1999; Huber and Shipan 2002). One way to incorporate this into the model would be to allow the agency to shift policy spatially for a cost. This could be done by either allowing the agency to move policy freely within a discretionary window (whether the window is endogenous or not) but pay a cost to set policy outside of the window or by introducing a marginal cost that is increasing in how far the agency moves policy (see e.g., Gailmard 2002; Lowande 2018).

This would allow for the trade-offs across unilateral action and statutory policymaking to also depend on the implementing agency's mission or ideal point. It also incorporates a 
secondary substantive dimension over which statutes and unilateral action may differ. In many policy areas it may be reasonable to assume that unilateral action can be pursued with a relatively tighter discretionary window due to the president's own discretion inherent to the policy tool itself. The collective action problems that must be overcome to pass comprehensive statutes can reasonably be thought to inject more ambiguity into the statement of policy goals, which creates more discretion from the bureaucracy's perspective. However one might go about incorporating a strategic bureaucratic actor, this would be a particularly fruitful avenue to continue to develop insights into the role of bureaucracy in shaping the incentives for different types of executive policymaking.

\section{Oversight and monitoring.}

Once a strategic agency is introduced, monitoring becomes potentially important for outcomes. Limiting discretion may not be very effective in constraining the agency if there is no effective oversight to enforce discretionary limits. In this essay oversight issues are collapsed into $p$, the measure of executive order durability. In that sense, $p$ captures judicial review prospects, public constraints, or even perhaps congressional oversight of bureaucratic actions. However, it misses the agency problems between the president and the bureaucracy. Even if presidents can bypass Congress by pursuing unilateral action they still must rely on the bureaucracy to effectively implement those policies, which creates room for the problems highlighted in a voluminous literature on principal-agent problems involving bureaucracy (see e.g., Bendor, Glazer, and Hammond 2001; Gailmard and Patty 2013a, 2013b; Miller 2005). To that end, it would be fruitful to incorporate oversight into the baseline framework explicitly. This also naturally dovetails with conceptions of bureaucratic discretion discussed above. The more 
difficult oversight becomes the more real discretion the bureaucracy has, holding fixed formal limits on discretion. Moreover, insofar as one policy instrument is more easily monitored another potential trade-off is introduced that could affect the executive's incentives to pursue one policy instrument over another. For example, it could be that executive orders are easier to monitor than their legislative counterparts since legislation tends to be more ambiguous and sprawling. Incorporating these dynamics into the argument would be a step toward understanding how differences in monitoring impact executive unilateralism.

\section{Other political actors.}

While I have focused on interbranch bargaining between the president and Congress, in the shadow of bureaucratic implementation, there are myriad other actors that might be profitably included in a model that extends the baseline model presented here. As noted above, recent work has explored the role of the public in structuring incentives for unilateral action (e.g., Judd 2017). Similarly, other work has explored how interest group dynamics affect the relative durability of statutes versus unilateral action (Foster 2019). One could also incorporate the public or interest groups as overseers of the bureaucracy. In that sense, the bureaucracy would be (potentially) constrained by the threat of a fire alarm alerting the president, or Congress, or both of agency subversion regardless of policy instrument (McCubbins and Schwartz 1984).20 Similarly, explicit incorporation of judicial review is a promising extensions.21 As previous work has shown the presence of effective judicial review can have profound impacts on bureaucratic

20 This could also, conceptually, partially capture the usage of administrative procedures to structure agency discretion á la Bawn 1995 and McCubbins, Noll, and Weingast 1987. 21 Of course, previous work has done so without also incorporating the bureaucracy and endogenous incentives. For a seminal example see Howell 2003. 
policymaking incentives, both positive and negative (Bueno de Mesquita and Stephenson 2007; Gailmard and Patty 2017; Patty and Turner 2019; Shipan 1997, 2000; Turner 2017, 2019a, 2019b). This may be particularly interesting since judicial oversight is separate from consideration of the ability of Congress or the president to monitor while also bargaining over policy. The presence of judicial oversight of the agency may differentially benefit Congress or the president in ways that alter the relative appeal of unilateral action.

\section{Conclusion}

In this essay I presented a simple model of interbranch bargain that incorporates two stylized facts - executive unilateral action is relatively less durable than legislation and investments bureaucratic agencies make toward implementing policy effectively are endogenous. I show that the nature of interbranch bargaining between Congress and the president, and therefore the appeal of unilateral action, depends critically on how these two dynamics interact with one another. Specifically, high bureaucratic capacity makes legislation more attractive to both the president and Congress. The better the bureaucracy is at implementing high quality policy the more important the added durability of passing legislation becomes. The relative lack of policy durability associated with unilateral action only affects the president's incentives to bypass Congress and issue an executive order. The more durable executive orders become - e.g., higher presidential approval, stronger discretionary claims, early in presidential term - the less likely it is that the president will find cooperation with Congress palatable. Conversely, as unilateral action becomes more precarious in terms of the likelihood it lasts the more willing the president is to bargain successfully with Congress, even when that requires sacrificing on spatial policy. 
Of course, the model in this essay abstracts from many important, and interesting, political dynamics. The model is tractable and flexible enough to incorporate many more substantive extensions of interest. Future work would do well to incorporate more strategic bureaucratic policymaking, agency discretion dynamics, electoral considerations, oversight and monitoring processes, and/or other political actors such as interest groups. However, in all of these richer environments the fundamental point from this essay remains: to fully understand whether and when unilateral action is attractive to chief executives one must take into account the fact that bargaining takes place in the shadow of bureaucracy.

\section{References}

Bawn, Kathleen. 1995. "Political Control Versus Expertise: Congressional Choices about Administrative Procedures.” American Political Science Review 89(1): 62-73.

Bendor, Jonathan, Amihai Glazer, and Thomas Hammond. 2001. "Theories of Delegation." Annual Review of Political Science 4 (1): 235-69.

Bolton, Alexander, and Sharece Thrower. 2016. "Legislative Capacity and Executive Unilateralism.” American Journal of Political Science 60: 649-63.

Bueno de Mesquita, Ethan, and Matthew C. Stephenson. 2007. "Regulatory Quality Under Imperfect Oversight.” American Political Science Review 101 (3): 605-20.

Burke, John P. 2000. The Institutional Presidency: Organizing and Managing the White House from FDR to Clinton. Baltimore, MD: Johns Hopkins University Press.

Callander, Steven. 2011. "Searching for Good Policies." American Political Science Review 105 (4): 643-62.

Canes-Wrone, Brandice. 2006. Who Leads Whom? Presidents, Policy, and the Public. Chicago, 
IL: University of Chicago Press.

Carpenter, Daniel P. 2001. The Forging of Bureacuratic Autonomy: Reputations, Networks, and Policy Innovation in Executive Agencies, 1862-1928. Princeton, NJ: Princeton University Press.

Chiou, Fang-Yi, and Lawrence S. Rothenberg. 2014. "The Elusive Search for Presidential Power." American Jounal of Political Science 58: 653-68.

—. 2017. The Engima of Presidential Power: Parties, Policies, and Strategic Uses of Unilateral Action. New York, NY: Cambridge University Press.

Christenson, Dino P., and Douglas L. Kriner. 2017a. "Mobilizing the Public Against the President: Congress and the Political Costs of Unilateral Action." American Journal of Political Science 61 (4): 769-85.

—. 2017b. "The Specter of Supreme Court Criticism: Public Opinion and Unilateral Action." Presidential Studies Quarterly 47 (3): 471-93.

_ 2019. "Does Public Opinion Contrain Presidential Unilateralism.” American Political Science Review.

Cooper, Phillip J. 2001. “The Law: Presidential Memoranda and Executive Orders: Of Patchwork Quilts, Trump Cards, and Shell Games.” Presidential Studies Quarterly 31 (1): 12641.

- 2002. By Order of the President. Lawrence, KS: University of Kansas Press.

Dickinson, Matthew J. 2009. "We All Want a Revolution: Neustadt, New Institutionalism, and the Future of Presidency Research.” Presidential Studies Quarterly 39: 736-70.

Dickinson, Matthew J., and Andrew Rudalevige. 2004. "Presidents, Responsiveness, and 
Competence: Revisiting the 'Golden Age' at the Bureau of the Budget.” Political Science Quarterly 119: 633-54.

Epstein, David, and Sharyn O'Halloran. 1994. “Administrative Procedures, Information, and Agency Discretion: Slack vs. Flexibility.” American Journal of Political Science 38 (3): $697-$ 722.

_ 1995. "A Theory of Strategic Oversight: Congress, Lobbyists, and the Bureaucracy." Journal of Law, Economics, \& Organization 11 (2): pp. 227-55.

-1999. Delegating Powers: A Transaction Cost Politics Approach to Policy Making

Under Separate Powers. New York, NY: Cambridge University Press.

Foster, David R. 2019. "Policy Feedback and Presidential Unilateral Action.” Unpublished Manuscript. University of California, Berkeley.

Gailmard, Sean. 2002. "Expertise, Subversion, and Bureaucratic Discretion.” Journal of Law, Economics, \& Organization 18 (2): 536-55.

Gailmard, Sean, and John W. Patty. 2007. "Slackers and Zealots: Civil Service, Policy Discretion, and Bureaucratic Expertise.” American Journal of Political Science 51 (4): 873-89. __ 2013a. "Formal Models of Bureaucracy." Annual Review of Political Science 15: 35377.

-2013b. Learning While Governing: Expertise and Accountability in the Executive Branch. Chicago, IL: University of Chicago Press.

—. 2017. "Participation, Process, \& Policy: The Informational Value of Politicized Judicial Review." Journal of Public Policy 37 (3): 233-60. 
Hirsch, Alexander V., and Kenneth W. Shotts. 2012. "Policy Specific Information and Informal Agenda Power.” American Journal of Political Science 56 (1): 67-83.

—. 2015. “Competitive Policy Development." American Economic Review 105 (4): 164664.

—. 2018. "Policy-Development Monopolies: Adverse Consequences and Institutional Responses.” Journal of Politics 80 (4): 1339-54.

Hitt, Matthew P., Craig Volden, and Alan E. Wiseman. 2017. "Spatial Models of Legislative Effectiveness." American Journal of Political Science 61 (3): 575-90.

Howell, William G. 2003. Power Without Persuasion. Princeton, NJ: Princeton University Press. —. 2005. "Unilateral Powers: A Brief Overview.” Presidential Studies Quarterly 35: 41739.

Howell, William G., and Kenneth R. Mayer. 2005. “The Last One Hundred Days.” Presidential Studies Quarterly 35 (3): 533-53.

Howell, William G., and John C. Pevehouse. 2007. While Dangers Gather: Congressional Checks on Presidential War Powers. Princeton, NJ: Princeton, NJ: Princeton University Press. Huber, John, and Charles Shipan. 2002. Deliberate Discretion? The Institutional Foundations of Bureaucratic Autonomy. New York, NY: Cambridge University Press.

Hübert, Ryan, and Janna King Rezaee. 2019. "Going into Government: How Hiring from Special Interests Reduces Their Influence.” Unpublished Manuscript. University of California, Davis. https://bit.ly/33LrezV.

Judd, Gleason. 2017. "Showing Off: Promise and Peril in Unilateral Policymaking.” Quarterly 
Journal of Political Science 12 (2): 241-68.

Kennedy, Joshua B. 2015. “'Do This! Do That!' And Nothing Will Happen: Executive Orders and Bureaucratic Responsiveness." American Politics Research 43: 59-82.

Krause, George A. 2009. "Organizational Comlexity and Coordination Dilemmas in U.s. Executive Politics." Presidential Studies Quarterly 39: 74-88.

Krause, George A., and Brent M. Dupay. 2009. "Coordinated Action and the Limits of Presidential Control over the Bureaucracy: Lessons from the George W. Bush Presidency.” In President George W. Bush's Influence over Bureaucracy and Policy: Extraordinary Times, Extraordinary Powers, edited by Colin Provost and Paul Teske, 81-104. New York, NY: Palgrave.

Lewis, David E. 2003. Presidents and the Politics of Agency Design: Political Insulation in the Unired States Government Bureaucracy, 1946-1997. Stanford, CA: Stanford University Press.

Lewis, David E., and Terry M. Moe. 2014. "The Presidency and the Bureaucracy: The Levers of Presidential Control." In The Presidency and the Political System, 374-405. Washington, DC: CQ Press.

Londregan, John B. 2000. Legislative Institutions and Ideology in Chile. New York, NY:

Cambridge University Press.

Lowande, Kenneth. 2018. “Delegation or Unilateral Action?” Journal of Law, Economics, \& Organization 34 (1): 54-78.

Lowande, Kenneth, and Thomas Gray. 2017. "Public Perception of the Presidential Toolkit." Presidential Studies Quarterly 47 (3): 432-47.

Mayer, Kenneth R. 2001. With the Stroke of a Pen: Executive Orders and Presidential Power. 
Princeton, NJ: Princeton University Press.

—. 2009. "Going Alone: The Presidential Power of Unilateral Action." In The Oxford Handbook of the American Presidency, 427-98. Oxford University Press.

McCarty, Nolan. 2017. "The Regulation and Self-Regulation of a Complex Industry." Journal of Politics 79 (4): 1220-36.

McCubbins, Mathew, Roger Noll, and Barry Weingast. 1987. “Administrative Procedures as Instruments of Political Control." Journal of Law, Economics, and Organization 3 (2): 243-77. McCubbins, Mathew, and Tom Schwartz. 1984. “Congressional Oversight Overlooked: Police Patrols versus Fire Alarms.” American Journal of Political Science 28: 165-79.

Miller, Gary J. 1993. Managerial Dilemmas: The Political Economy of Hierarchy. New York, NY: New York, NY: Cambridge University Press.

—. 2005. "The Political Evolution of Principal-Agent Models." Annual Review of Political Science 8: 203-25.

Moe, Terry, and William Howell. 1999. "The Presidential Power of Unilateral Action.” Journal of Law, Economics, and Organization 15(1): 132-79.

Nathan, Richard P. 1983. The Administrative Presidency. Upper Saddle River, NJ: Prentice Hall. O’Brien, Patrick R. 2017. “The Historical Presidency: A Theoretical Critique of the Unitary Executive Framework: Rethinking the First-Mover Advantage, Collective-Action Advantage, and Informational Advantage.” Presidential Studies Quarterly 47 (1): 169-85.

Patty, John W., and Ian R. Turner. 2019. “Ex Post Review and Expert Policymaking: When Does Oversight Reduce Accountability?" Journal of Politics. 
Potter, Rachel Augustine. 2019. Bending the Rules: Procedural Politicking in the Bureaucracy. Chicago, IL: University Of Chicago Press.

Reeves, Andrew, and Jon C. Rogowski. 2015. "Public Opinion Toward Presidential Power." Presidential Studies Quarterly 45 (4): 742-59.

_ 2016. "Unilateral Powers, Public Opinion, and the Presidency." Journal of Politics 78 (1): 137-51.

—. 2018. "The Public Cost of Unilateral Action.” American Journal of Political Science 62 (2): 424-40.

Rudalevige, Andrew. 2009. “The Administrative Presidency and Bureaucratic Control: Implementing a Research Agenda." Presidential Studies Quarterly 39: 10-24.

—. 2012. "Executive Orders and Presidential Unilateralism." Presidential Studies Quarterly, 138-60.

Shipan, Charles R. 1997. Designing Judicial Review: Interest Groups, Congress, and Communications Policy. Ann Arbor, MI: University of Michigan Press.

—. 2000. "The Legislative Design of Judicial Review: A Formal Analysis." Journal of Theoretical Politics 12 (3): 269-304.

Thrower, Sharece. 2017. "To Revoke or Not Revoke? The Political Determinants of Executive Order Longevity.” American Journal of Political Science 61 (3): 642-56.

Ting, Michael M. 2011. “Organizational Capacity.” Journal of Law, Economics, \& Organization 27 (2): $245-71$.

Turner, Ian R. 2017. "Working Smart and Hard? Agency Effort, Judicial Review, and Policy 
Precision." Journal of Theoretical Politics 29 (1): 69-96.

https://doi.org/10.1177/0951629816630430.

_ 2019a. "Political Agency, Oversight, and Bias: The Instrumental Value of Politicized Policymaking." Journal of Law, Economics, \& Organization.

—. 2019b. "Reviewing Procedure Vs. Judging Substance: The Scope of Review and Bureaucratic Policymaking." Unpublished Manuscript. Yale University.

Wood, B. Dan. 2008. The Politics of Economic Leadership: The Causes and Consequences of Presidential Rhetoric. Princeton, NJ: Princeton University Press.

Zeisberg, Mariah. 2013. War Powers: The Politics of Constitutional Authority. Princeton, NJ:

Princeton University Press.

\section{Appendix}

Proposition 1. For all $p \in(0,1)$, the agency's quality investment is always lower following an executive order than a statute: $q_{S}^{*}>q_{E O}^{*}$. Moreover, $q_{E O}^{*} \rightarrow 0$ as $p \rightarrow 0$ and $q_{E O}^{*} \rightarrow q_{S}^{*}$ as $p \rightarrow 1$.

Proof. When the agency is asked to implement a statute it maximizes the following:

$$
\max _{q_{S}}\left[q_{S}-\left(x_{S}^{*}-A\right)^{2}-\frac{q_{S}^{2}}{2 \lambda}\right]
$$

Taking the first-order condition and solving for qyields the equilibrium capacity investment when a statute is passed $q_{S}^{*}$ :

$$
\begin{aligned}
1-\frac{q_{S}}{\lambda} & =0 \\
q_{S}^{*} & =\lambda .
\end{aligned}
$$

For completeness, note that the second-order condition is $-\frac{1}{\lambda}<0($ since $\lambda>0)$ so we have a 
maximum. Thus, when a statute is passed the agency invests $q_{S}^{*}=\lambda$ toward quality implementation. Obviously, as $\lambda$ increases, quality costs decrease so the agency invests more. Now consider the case in which an executive order is issued. In that case the agency maximizes its utility by solving the following problem:

$$
\max _{q_{E O}}\left[p\left(q_{E O}-\left(x_{E O}^{*}-A\right)^{2}\right)-(1-p)\left(x_{Q}^{*}-A\right)^{2}-\frac{q_{E O}^{2}}{2 \lambda}\right]
$$

Taking the first-order condition and solving for qyields the equilbirium capacity investment when an executive order is issued, $q_{E O}^{*}$ :

$$
\begin{aligned}
p-\frac{q_{E O}}{\lambda} & =0, \\
q_{E O}^{*} & =p \lambda .
\end{aligned}
$$

The second-order condition is again $-\frac{1}{\lambda}<0$ so we have a maximum. When an EO is issued the agency invests $p \lambda$ toward quality. Obviously this implies that quality following an EO is increasing in $\lambda$ (as costs decrease) and $p$ (as the EO becomes more durable). Finally, inspection of the optimal quality investments shows that $q_{E O}^{*} \rightarrow 0$ as $p \rightarrow 0$ and $q_{E O}^{*} \rightarrow q_{S}^{*}$ as $p \rightarrow 1$.

Lemma 1. Define $\Delta_{C}:=\sqrt{q_{S}^{*}+\left(x_{Q}-C\right)^{2}}$. In equilibrium, Congress accepts a proposed statute $x_{S}$ if and only if $x_{S} \in\left[C-\Delta_{C}, C+\Delta_{C}\right]$. Otherwise, Congress rejects the proposed statute and the status quo obtains. The range $\left[C-\Delta_{C}, C+\Delta_{C}\right]$ is increasing in Agency quality investments $q_{S}^{*}=$ $\lambda$ and the distance between the status quo and Congress's ideal point $\left|x_{Q}-C\right|$.

Proof. Incentive compatibility requires that $E U_{C}\left(\operatorname{accept} \mid x_{S}, q_{S}^{*}\right) \geq E U_{C}\left(\right.$ reject $\left.\mid x_{S}, q_{S}^{*}\right)$ hold for Congress to accept a proposed statute $x_{S}$. This requires that,

$$
q_{S}^{*}-\left(x_{S}-C\right)^{2} \geq-\left(x_{Q}-C\right)^{2}
$$


which is satisfied for all $x_{S} \in\left[C-\sqrt{q_{S}^{*}+\left(x_{Q}-C\right)^{2}}, C+\sqrt{q_{S}^{*}+\left(x_{Q}-C\right)^{2}}\right]$. The result follows once we define $\Delta_{C}:=\sqrt{q_{S}^{*}+\left(x_{Q}-C\right)^{2}}$. Finally, inspection of $\Delta_{C}$ shows that the range is increasing in $q_{S}^{*}=\lambda$ and decreasing as $x_{Q} \rightarrow C$ (or increasing as $\left|x_{Q}-C\right|$ increases).

Lemma 2. In equilibrium, the President will propose a statute $x_{S}^{*}$, rather than issue an executive order, if and only if $x_{S}^{*} \in\left[P-\Delta_{P}, P+\Delta_{P}\right]$. The range $\left[P-\Delta_{P}, P+\Delta_{P}\right]$ is increasing in Agency quality investment $q_{S}^{*}=\lambda$ and the distance of the status quo from the President's ideal point $\left|x_{Q}-P\right|$, and decreasing in executive order durability $p$.

Proof. Lemma 4 shows that the President will not propose a statute that would be rejected by Congress. Thus, the relevant incentive compatibility condition involves the President's payoff for proposing a statute that is accepted versus issuing an executive order that is at her ideal point. Formally:

$$
\begin{array}{ccc}
E U_{P}\left(x_{S} \mid q_{S}^{*}\right) & \geq & E U_{P}\left(x_{E O}=P \mid q_{E O}^{*}, p\right), \\
q_{S}^{*}-\left(x_{S}-P\right)^{2} & \geq p\left(q_{E O}^{*}-\left(x_{E O}-P\right)^{2}\right)+(1-p)\left(-\left(x_{Q}-P\right)^{2}\right), \\
q_{S}^{*}-p q_{E O}^{*} & \geq\left(x_{S}-P\right)^{2}-p\left(x_{E O}-P\right)^{2}-(1-p)\left(x_{Q}-P\right)^{2},
\end{array}
$$

which is satisfied for all $x_{S} \in\left[P-\sqrt{q_{S}^{*}-p q_{E O}^{*}+(1-p)\left(x_{Q}-P\right)^{2}}, P+\right.$ $\left.\sqrt{q_{S}^{*}-p q_{E O}^{*}+(1-p)\left(x_{Q}-P\right)^{2}}\right]$. Defining $\Delta_{P}:=\sqrt{q_{S}^{*}-p q_{E O}^{*}+(1-p)\left(x_{Q}-P\right)^{2}}$ completes the result. Finally, inspection of $\Delta_{P}$ shows that the range of acceptable statutes is increasing in Agency capacity $\lambda$ and the distance between the status quo and the President's ideal point $\mid x_{Q}-$ $P \mid$, and decreasing in executive order durability $p$.

Lemma 3. In equilibrium, if the President issues an executive order then she sets $x_{E O}^{*}=P$.

Proof. The President's expected utility for setting policy so that $x_{E O}^{*}=P$ is, 


$$
\begin{array}{rlc}
E U_{P}\left(x_{E O}^{*}=P \mid q_{E O}^{*}\right) & = & p\left(q_{E O}^{*}-\left(x_{E O}^{*}-P\right)^{2}\right)+(1-p)\left(-\left(x_{Q}-P\right)\right), \\
& = & p q_{E O}^{*}-p(P-P)-(1-p)\left(x_{Q}-P\right)^{2} \\
& = & p q_{E O}^{*}-(1-p)\left(x_{Q}-P\right)^{2}
\end{array}
$$

In contrast, her expected utility for deviating by $\delta>0$ so that $x_{E O}^{*}=P+\delta$ is,

$$
E U_{P}\left(x_{E O}^{*}=P+\delta \mid q_{E O}^{*}\right)=p q_{E O}^{*}-p \delta^{2}-(1-p)\left(x_{Q}-P\right)^{2} .
$$

Clearly, $E U_{P}\left(x_{E O}^{*}=P \mid q_{E O}^{*}\right)>E U_{P}\left(x_{E O}^{*}=P+\delta \mid q_{E O}^{*}\right)$ since $\delta>0$.

Lemma 4. In equilibrium, the President only proposes statutes that will be accepted by

Congress.

Proof. If the President were to propose a statute that is rejected by Congress then final policy is the status quo, $x_{Q}$. However, she could always instead issue an executive order, which in equilibrium will always target her ideal point $x_{E O}^{*}=P$ (see Lemma 3 ), and get positive quality investment from the Agency. Formally, this implies the following inequality must be satisfied:

$$
\begin{aligned}
q_{E O}^{*}-\left(x_{E O}^{*}-P\right)^{2} & \geq-\left(x_{Q}-P\right)^{2}, \\
p \lambda-(P-P)^{2} & \geq-\left(x_{Q}-P\right)^{2}, \\
p \lambda & \geq-\left(x_{Q}-P\right)^{2},
\end{aligned}
$$

which is always trivially satisfied since $p \in(0,1), \lambda>0$, and $-\left(x_{Q}-P\right)^{2} \leq 0$ for all $x_{Q}, P \in \mathbb{R}$.

Lemma 5. In equilibrium, if $x_{S}=P \in\left[C-\Delta_{C}, C+\Delta_{C}\right]$, which implies it will be accepted by Congress, then the President always proposes the statute $x_{S}^{*}=P$.

Proof. This follows directly from the fact that when $x_{S}=P$ will be accepted by Congress the President receives the same spatial policy payoff as she would from issuing an executive order (since $x_{E O}=x_{S}=P$ in this case) but gets strictly more quality from the Agency since $q_{S}^{*}=\lambda>$ $q_{E O}^{*}=p \lambda$. Thus, whenever $x_{S}=P$ will be accepted by Congress, which is the case so long as $P \in$ 
$\left[C-\Delta_{C}, C+\Delta_{C}\right]$, the President is always strictly better off pursuing a statute than an EO given that this induces higher capacity investments from the Agency.

Proposition 2. In equilibrium, the players play the following collection of strategies:

- The President proposes a statute $x_{S}^{*}$ if and only if $x_{S}^{*} \in\left[P-\Delta_{P}, P+\Delta_{P}\right]$ and it will be accepted by Congress. Otherwise, she issues an executive order targeting her ideal point, $x_{E O}^{*}=P$.

- Congress accepts a proposed statute $x_{S}$ if and only if $x_{S} \in\left[C-\Delta_{C}, C+\Delta_{C}\right]$. Otherwise, Congress rejects $x_{S}$ and the status quo $x_{Q}$ becomes final policy.

- $\quad$ The Agency invests $q_{S}^{*}=\lambda$ toward quality implementation when the policy it is implementing is a statute and invests $q_{E O}^{*}=p \lambda$ if the policy is an executive order.

Proof. The construction of the equilibrium follows from combining Lemma 3, Lemma 4, Lemma 2, Lemma 1, and Proposition 1. Specifically, Lemma 4 shows that the President only proposes statutes that Congress will accept and Lemma 2 derives the range of statutes that are incentive compatible for the President to propose assuming Congress will accept. Lemma 3 shows that when there is no statute that is incentive compatible for the President to propose and she instead issues an executive order, that EO will be at her ideal point. Lemma 1 derives the set of proposed statutes that Congress will accept over the status quo (which obtains if Congress rejects). Finally, Proposition 1 characterizes the Agency's optimal quality investments for statutes and executive orders.

Remark 1. All else equal, as agency capacity גincreases both Congress and the President become more willing to compromise on spatial policy to pass a statute.

Proof. This follows from straightforward comparative statics on $\Delta_{C}$ and $\Delta_{P}$ with respect to $\lambda$. 
Specifically,

$$
\frac{\partial \Delta_{C}}{\partial \lambda}=\frac{1}{2 \sqrt{\lambda+\left(x_{Q}-C\right)^{2}}}
$$

which is strictly positive since $\lambda>0$. Now consider $\Delta_{P}$.

$$
\frac{\partial \Delta_{P}}{\partial \lambda}=\frac{1-p^{2}}{2 \sqrt{\lambda\left(1-p^{2}\right)+(1-p)\left(x_{Q}-P\right)^{2}}}
$$

which is strictly positive since $p \in(0,1)$ and $\lambda>0$.

Remark 2. All else equal, as executive order durability increases, $p \rightarrow 1$, the President is less willing to compromise on policy location in order to pass a statute and as executive order durability decreases, $p \rightarrow 0$, the President is more willing to compromise on policy location in order to have a statute implemented.

Proof. This follows from comparative statics on $\Delta_{C}$ and $\Delta_{P}$ with respect to $p$. First, note that $p$ does not appear in $\Delta_{C}:=\sqrt{q_{S}^{*}+\left(x_{Q}-C\right)^{2}}$ so $\Delta_{C}$ is not affected by changes in $p$. Now, consider $\Delta_{P}:$

$$
\frac{\partial \Delta_{P}}{\partial p}=\frac{-\left(x_{Q}-P\right)^{2}-2 p \lambda}{2 \sqrt{\lambda\left(1-p^{2}\right)+(1-p)\left(x_{Q}-P\right)^{2}}}
$$

which is negative for all $p \in(0,1)$ and $\lambda>0$. 